\title{
DELITOS EN LA PROVINCIA
}

\section{TUNGUBAHUA}

La Infracción penal (delito) es la conducta típica, antijurídica y culpable cuya sanción se prevé en el Art. 18 del Código Orgánico integral Penal (COIP) del Ecuador.

Las infracciones de acuerdo al Art. 19 del COIP se clasifican en delitos y contravenciones, la primera es la infracción penal sancionada con pena privativa de libertad mayor a treinta días; mientras que, la segunda es la infracción penal sancionada con pena no privativa de libertad o privativa de libertad de hasta treinta días.

La potestad de investigar y perseguir la sanción de los delitos le corresponde a la Fiscalía, cuando tenga los elementos de convicción suficientes sobre la existencia de la infracción y de la responsabilidad de la persona procesada, pudiendo abstenerse de ejercer la acción penal, cuando se puede aplicar el principio de oportunidad, se presente una causal de prejudicialidad, procedibilidad o cuestiones previas.

En un estudio trimestral comparativo publicado por el Ministerio Coordinador de Seguridad se detalla a los delitos de mayor influencia a Nivel Nacional, los siguientes:

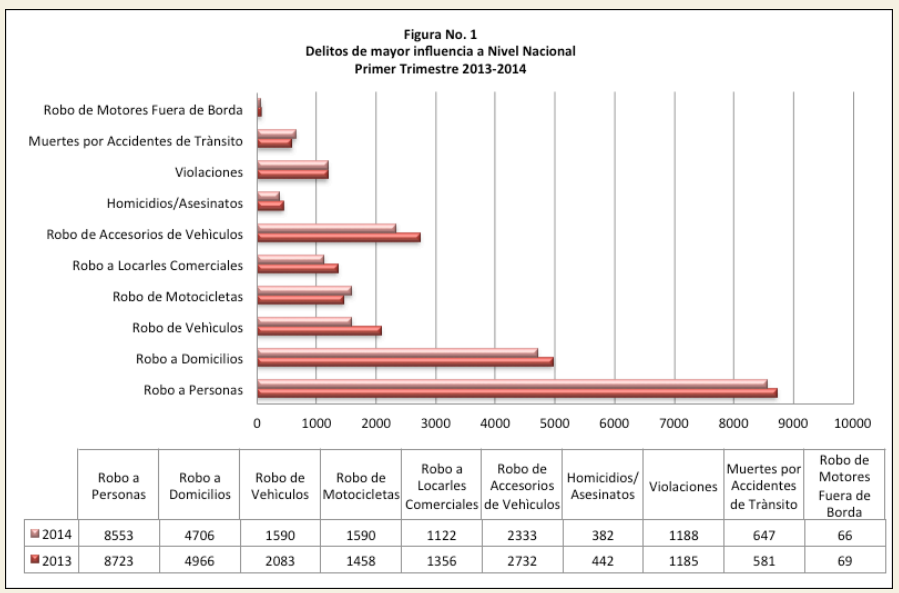

Fuente: Estadísticas CEASI - Ministerio Coordinador de Seguridad Elaboración: Equipo Técnico OBEST
En el comparativo de los años 2013 - 2014 se puede diferenciar que uno de los delitos más frecuentes es el robo a personas con $36,7 \%$ y $38,57 \%$, seguido por robo a domicilios $21,22 \%$ y $21,05 \%$ respectivamente, con respecto al porcentaje total de delitos a nivel nacional por año.

Se describe que el robo de accesorios de vehículos en el primer trimestre del 2013 fue de 2.732 frente a 2.333 denuncias en el año 2014, registrando una disminución del 14,6\%.

En resumen los delitos detallados disminuyeron en un promedio anual de 11,5\%, exceptuando muertes por accidentes de tránsito y robo de motocicletas que presentaron un aumento de $10 \%$ promedio anual.

\section{DELITOS EN LA PROVINCIA DE TUNGURAHUA}

\section{DELITOS PENALES}

Los cinco tipos de delitos con mayor número de denuncias en la provincia de Tungurahua según la Fiscalía Provincial de Tungurahua. (ver figura No. 2)

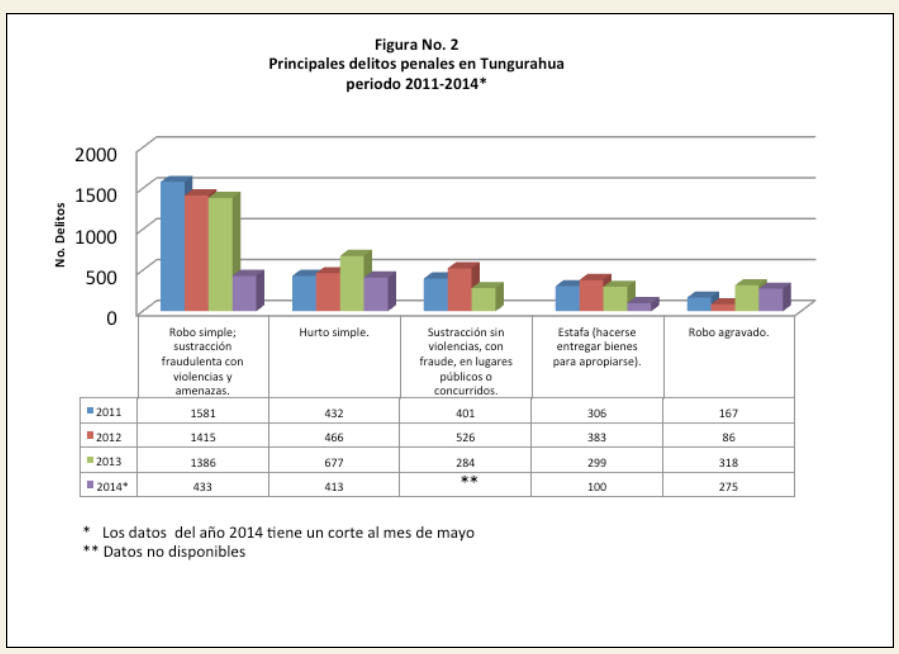

Fuente: Fiscalia Provincial de Tungurahua.

Elaboración: Equipo Técnico OBEST 
Los delitos representados en la figura No. 2 son delitos contra el Derecho a la Propiedad, los promedios anuales de denuncias que sobresalen en el periodo 2011- 2013 en la Provincia de Tungurahua son: Robo Simple con 1.461 denuncias, que impone una condena de 3 a 5 años de privación de libertad (Art. 189); el hurto simple con 525 , cuya sanción esta reprimida con pena de libertad de 6 meses a 2 años (Art. 196); sustracción sin violencias (con fraude, en lugares públicos o concurridos) registra 404, sancionado con una pena de 6 meses a 2 años de prisión (Art. 196); estafa 329, sancionada con pena privativa de libertad de 5 a 7 años (Art. 186); y, Robo agravado con 190, con pena privativa de libertad de 5 a 7 años (Art. 189).

Con relación al periodo 2011-2013 se estima que para finales del 2014, se alcanzarían las siguientes cifras aproximadas: robo simple (sustracción fraudulenta con violencias y amenazas) llegarían a 1.266 denuncias; hurto simple 770; estafa 322 ; y, robo agravado 341 denuncias.

\section{PRINCIPALES DELLTOS DE ADOLESCENTES INFRACTORES}

El Artículo 4 del Código de la Niñez y la Adolescencia, define como Adolescente a la persona entre 12 y 18 años de edad. Establece que los adolescentes son penalmente inimputables y por tanto, no serán juzgados por jueces penales ordinarios ni se les aplicará las sanciones previstas en las leyes penales (Art. 305).

Los delitos más frecuentes en adolescentes infractores en la Provincia de Tungurahua, de acuerdo a los datos entregados por la Fiscalía Provincial de Tungurahua son: robo simple (sustracción fraudulenta con violencias y amenazas), hurto simple y violación. (ver figura No.3)

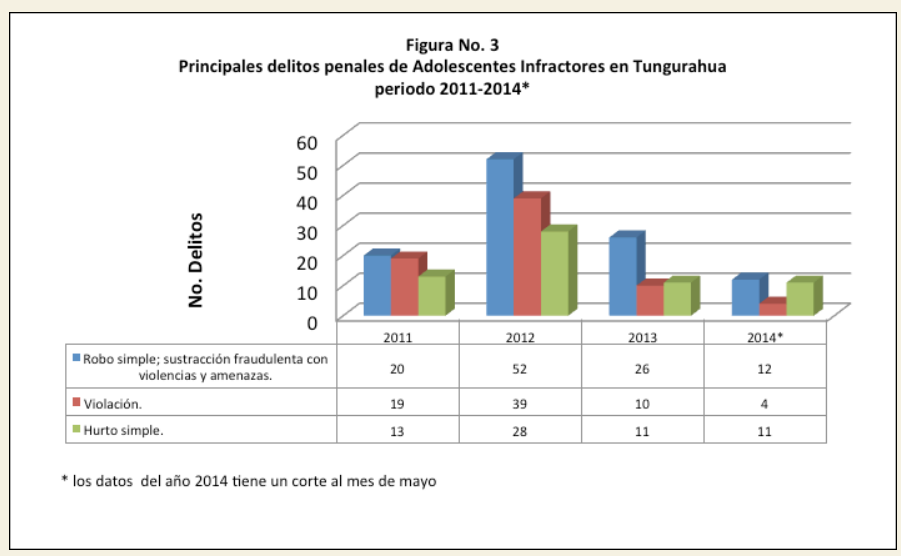

Fuente: Fiscalia Provincial de Tungurahua.

Elaboración: Equipo Técnico OBEST
Los promedios de delitos de adolescentes infractores que sobresalen en el periodo 2011- 2013 son: Robo simple (sustracción fraudulenta con violencias y amenazas) con un promedio anual de 33 denuncias, penado con internamiento semi abierto de 3 meses a 1 año; violación registra 23 casos sancionado de 4 a 8 años de internamiento; y, hurto simple con 17 denuncias promedio anual, sancionado con libertad asistida de 3 meses a 1 año.

Con relación a los datos comprendidos en el periodo 2011-2013 se estima que a finales del año 2014 alcanzará aproximadamente a 39 denuncias de robo simple, 14 violaciones y 15 casos de hurto simple, evidenciando un incremento en el primer delito y un decremento para los dos restantes.

\section{PRINCIPALES DELITOS DE TRÁNSITO}

El COIP define a las Infracciones de Tránsito (Art. 371), como la acción u omisión culposa producidas en el ámbito del transporte y seguridad vial.

Las infracciones más frecuentes son: los delitos que tienen como resultado daños materiales cuya reparación sea mayor a 2 Salarios Básicos Unificados (SBU) del trabajador en general serán sancionados con multa de 2 SBU del trabajador en general, y reducción de 6 puntos en su licencia de conducir.

Cuando los daños superen los 6 SBU, serán sancionados con multa de 4 SBU y reducción de 9 puntos en su licencia de conducir (Art. 380).

Los delitos de tránsito en los que se tenga como resultado lesiones causadas por accidente de tránsito (Art. 379), serán sancionados conforme lo prevé el Art. 152 del COIP reducidas en un cuarto de la pena mínima prevista en cada caso, son los delitos de tránsito que se verifican en segundo lugar de incidencia.

Finalmente se encuentra aquellos establecidos en el Art. 377 del COIP que tipifica la muerte culposa ocasionada por infringir el deber objetivo de cuidado y será sancionado con pena privativa de libertad de 1 a 3 años, suspensión de la licencia de conducir por 6 meses una vez cumplida la pena privativa de libertad. Cuando se verifiquen que el delito es producto de acciones innecesarias, peligrosas e ilegítimas la pena será de 3 a 5 años.

Según datos proporcionados por la Fiscalía Provincial, Tungurahua registra las siguientes infracciones de tránsito: (ver Figura No. 4) 


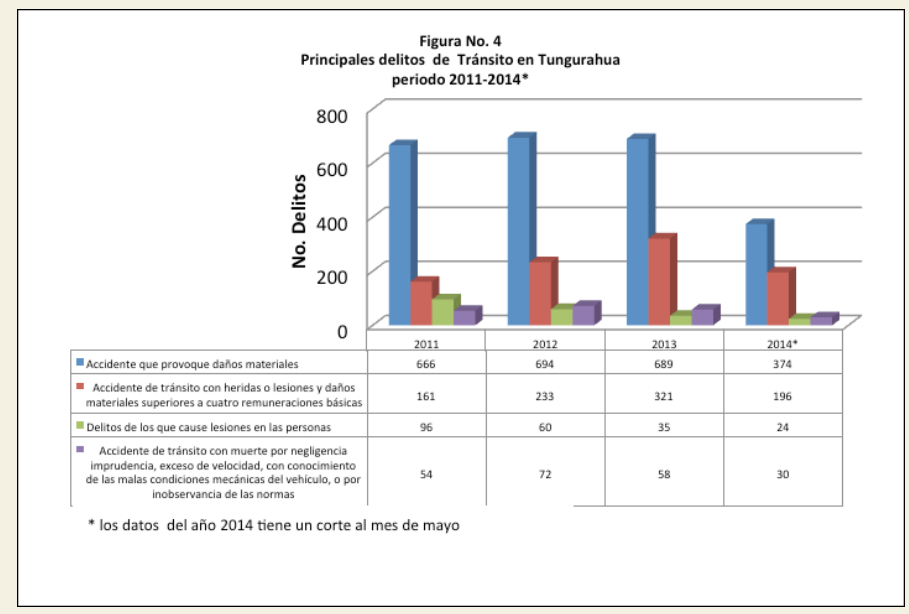

Fuente: Fiscalia Provincial de Tungurahua

Elaboración: Equipo Técnico OBEST

El promedio de los delitos de tránsito en el periodo 2011- 2013 son: Accidentes que provocan daños materiales con 683 casos, accidente de tránsito con heridas o lesiones y daños materiales superiores a cuatro remuneraciones básicas 238 casos; delitos que causen lesiones en las personas 64 casos; y, accidente de tránsito con muerte por negligencia o imprudencia, exceso de velocidad, malas condiciones mecánicas del vehículo, o por inobservancia de las normas registra 61 casos.
Con relación al periodo 2011-2013 se estimaría que para finales del 2014, los accidentes que provoquen daños materiales llegarían a 706 casos, los accidentes con heridas o lesiones y daños materiales a 398 casos, y los accidentes de tránsito con muerte tendrían 65 casos en el año.

\section{Referencia:}

Ministerio Coordinador de Seguridad, Estadísticas de Seguridad Integral, 1er trimestre 2014

Fiscalía Provincial de Tungurahua

Código Orgánico Integral Penal (COIP)

Observatorio Económico y Social de Tungurahua (OBEST) - Universidad Técnica de Ambato

\section{Lic. Sandra Garcés}

Econ. Juan Pablo Martínez

Colaboradores:

Dr. Ramiro Tite

Ing. Jorge Tamayo

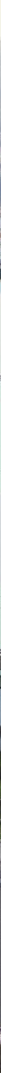

